\title{
REPORT ON THE WORKSHOP ON THE INTERNATIONAL COLLABORATIVE STUDY
}

\section{E M SCOTT}

A workshop chaired by the organizers of the International Collaborative Study was held at the Dubrovnik Conference. This meeting provided an opportunity for the ${ }^{14} \mathrm{C}$ community to discuss the details of the study and the interpretations of the results.

The relationship between the results for Stages 1 and 2, the comparability of different laboratory types and plans for future work were of particular interest to the meeting.

Several important points concerning the operation of the study were raised. The need for a rapid response by the organizers when results were submitted was emphasized by participants. The organizers said this would be taken into account in Stage 3.

The use of known-age samples (ages which are known through other than radiometric measurement) was felt to be particularly important. Participants were reminded of the presence of four known-age samples, provided by the Belfast dendrochronology laboratory.

The participation of accelerator laboratories in the study was discussed and it was a generally agreed that their representation was important in such work. It had become clear that additional care should be given to samples submitted to accelerator laboratories.

The final discussion centered around plans for future work. There was considerable interest in continuing the work of the Collaborative Study. Many felt that a regular system of intercalibration was required. A sug-

tion was made that a workshop should be held on completion of the Collaborative Study, at which time, with all relevant information available, detailed plans could be drawn up outlining future work in this area. The study organizers supported this idea, and suggested that such a meeting be held in Glasgow in 1989.

The meeting finished with general agreement that

1) the study should continue, and all laboratories be encouraged to complete the remaining stages,

2) a workshop be organized in 1989 in Glasgow,

3) plans for future work should be drawn up at the workshop in light of all available evidence. 